4. CONDE, J.M.; ESPINOSA, J.; CAMACHO, E. y cols.: "Schwannoma presacro benigno que provoca uropatía obstructiva. Caso clínico y revisión de la literatura". Actas Urol. Esp., 25: 237, 2001.

5. POZO, B.; PÉREZ, I.; FERNÁNDEZ, E. y cols.: "Schwannoma retroperitoneal benigno en paciente con antecedentes de tumor de Wilms en la infancia". Actas Urol. Esp., 27: 379, 2003.

6. VEGA, M.; ORLICH, C.; VALVERDE, H.: "Schwannoma de colon. Reporte de un caso". Acta Médica Costarricense 45, 2: 77, 2003.

7. ESCLARIN, M.A.; SANZ, J.I.; ORTAS J.L.. y cols.: "Tumor retroperitoneal infrecuente: schwannoma benigno". Actas Urol. Esp., 15: 577, 1991.

8. GIRONÉS, J.; ROIG, J.; RODRÍGUEZ, J.I. y cols.: "Schwannoma retroperitoneal maligno asociado a neurofibromatosis". Cirugía Española, volumen 73, $n^{\circ} 4$ : 255, 2003.

**9. BALIBREA, J.L.: "Afecciones quirúrgicas retroperitoneales". En Tratado de Cirugía. Editorial Marban S.L. Madrid. España, 1943, 1994.

*10. GALOFRÉ, N.; SUPERVÍA, A.; PEÑA, M.J. y cols.: "Schwannoma benigno retroperitoneal". An. Med. Int. Madrid, 13: 568, 1996.

Casos C línicos

Arch. Esp. Urol., 58, 2 (167-170), 2005

\section{GANGRENA DE FOURNIER SECUNDARIA A CATETERISMO URETRAL}

José Carlos López Pacios², José M aría Sánchez $M_{\text {erino }}{ }^{1}, M$. C armen Piñeiro Fernández ${ }^{2}, M$. Bouso M ontero ${ }^{3}$, Luis Parra M untaner ${ }^{1}$ y Jesús $G$ arcía Alonso ${ }^{1}$.

Servicios de Urología ${ }^{1}$ Urgencias $s^{2}$ Ana tomía Patológica ${ }^{3}$ del Hospital del Bierzo. FuentesnuevasPonferrada. León. España.

José Carlos López Pacios

C/ Ancha $1450 \mathrm{~A}$

24400 PO N FERRADA.

León. España

Trabajo recibido: 30 de junio 2004
Resumen.- O BJETIVO S: M ediante el forma to de caso clínico presentamos un caso de $G$ angrena de Fournier secundario a cateterismo uretral.

M ÉTO DO S: Realizamos una descripción del caso clínico que nos ocupa, en el que se ha identificado la causa inicial, así como una breve revisión bibliográfica de esta patología.

RESULTADO : Aunque la gangrena de Fournier se consideraba inicialmente como de etiología idiopática, en la actualidad es posible identificar en la mayoría de los casos la puerta de entrada de la infección. En nuestro caso la colocación de un catéter uretral fue el mecanismo de inicio de la infección, asociado a dos factores como la diabetes y el alcoholismo que favorecen el desarrollo de la misma. Se trató mediante desbridamiento quirúrgico y se realizó uretrectomía parcial. El paciente fue finalmente exitus.

CON CLUSIO NES: Se debe llamar la atención sobre la necesidad de que la manipulación uretral sea realizada por manos expertas dada la gravedad de las posibles complicaciones.

Hay que insistir en la necesidad de un tratamiento precoz con una cobertura de antibióticos de amplio espectro, un desbridamiento radical y una revisión urológica completa.

Palabras clave: G angrena de Fournier. C ateterismo. Uretra.

Summary.- O BJECTIVES: W e report one case of Fournier's gangrene secondary to urethral catheterization. METHODS: W e describe the clinical case, in which the initial cause was identified, and perform a short bibliographic review.

RESULTS: Although Fournier's gangrene was initially considered as idiopathic in etiology, currently it is possible to identify the entrance site of the infection. In the present case the insertion of a urethral catheter was the starting mechanism, associated with factors such as diabetes and alcoholism which favour its development The patient was treated by surgical debridement and partial urethrectomy but finally died.

CON CLUSIO N S: W e want to point out that urethral instrumentation should be done by expert hands due to the severity of possible complications. We should insist in the need of precocious treatment with wide spectrum antibiotics, radical debridement and complete urologic evaluation. 
Keywords: Fournier's gangrene. Catheterization. Urethra.

\section{INTRODUCCIÓN}

La $\mathrm{G}$ angrena de Fournier se considera una Fascitis necrotizante infecciosa de pene, periné y escroto de inicio súbito y de rápida progresión. Inicia Imente descrita por Jean A lfred Fournier como de origen idiopático, hoy es posible identificar su origen en la mayoría de los casos. Puede afectar pacientes de cualquier edad y se ve favorecida por enfermedades y factores debilitantes como alcoholismo crónico o diabetes, teniendo una elevada tasa de mortalidad.

\section{CASO CĹNICO}

Paciente de 57 años de edad, que acudió al Servicio de Urgencias de nuestro Hospital por presentar fiebre eleva-

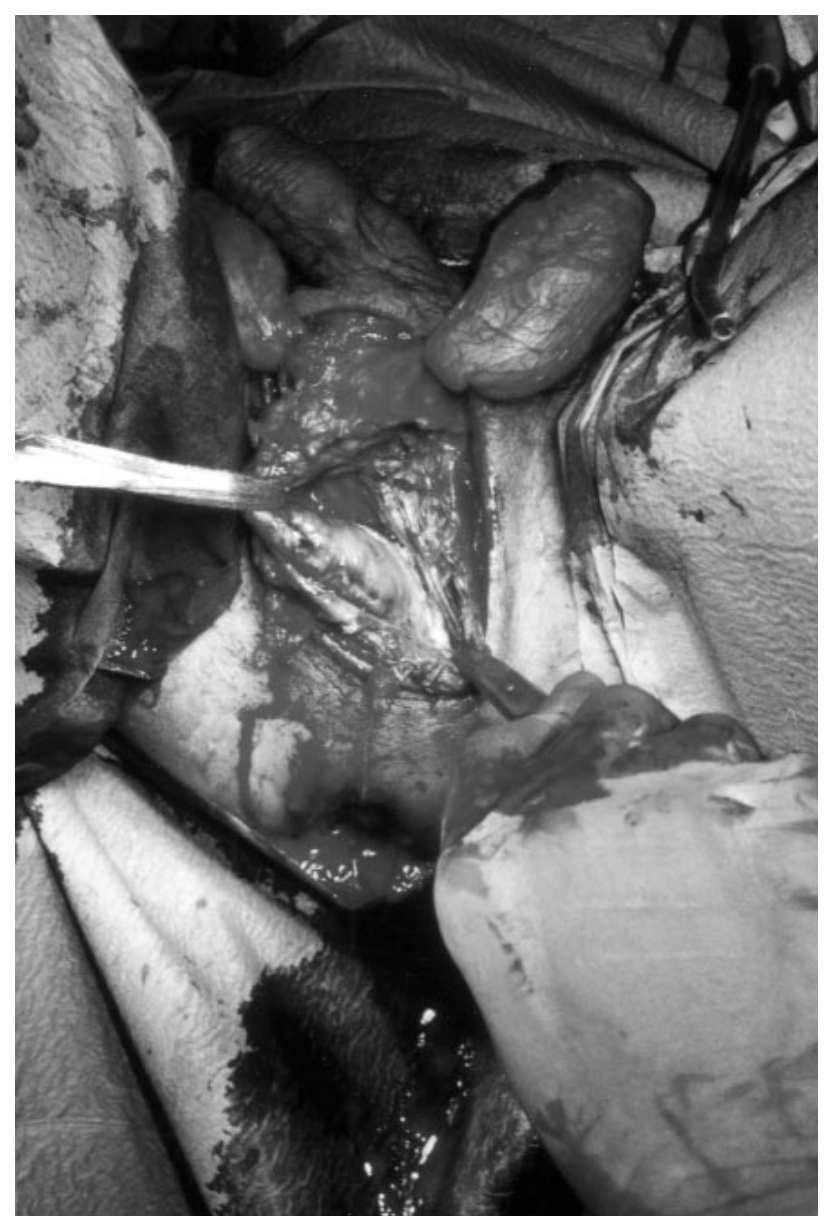

FIG URA 1. Imagen macroscópica de la intervención quirúrgica, mostrando el área desbridada. da $(38,5 \%)$, incontinencia urinaria y dolor e infla mación a nivel escrotal.

Como antecedentes personales figuraba etilismo crónico, diabetes mellitus insulinodependiente de 17 años de evolución, pancreatitis enólica crónica, fumador de 1 paquete/ día y retención urinaria que precisó sondaje vesical durante 3 días una semana antes del episodio actual.

En la exploración física encontramos una importante afectación del estado general con caquexia, deshidratación, abombamiento abdominal suprapúbico con percusión mate, lesión negruzca en la parte más declive del escroto, signos inflamatorios sin fluctuación a nivel perineal y celda prostática plana, no dolorosa en el tacto rectal.

Los hallazgos de laboratorio fueron los siguientes: Hemograma completo con una Hemoglobina de 10,7 $\mathrm{g} / \mathrm{dl}$, hematocrito 31,25 , leucocitos 40.700 con un $76 \%$ de segmentados y $10 \%$ de cayados. Bioquímica con: glucemia $497 \mathrm{mg} / \mathrm{dl}$, urea $67 \mathrm{mg} / \mathrm{dl}$ y creatinina 1,1 $\mathrm{mg} / \mathrm{dl}$. Estudio de coagulación: Tiempo de Q uick 29,6\%, IN R 2,41, Ptta 48,5 sg y Fibrinógeno de $976,9 \mathrm{mg} / \mathrm{dl}$. Se realizó una radiografía de abdomen que no mostró alteraciones.

Como prueba complementaria se hizo una ecografía escrotal y perineal donde se informó de la existencia de una retención urinaria, un pequeño hidrocele derecho y un engrosamiento importante de la piel escrotal y perineal.

Con estos hallazgos se diagnosticó al paciente de gangrena de Fournier iniciándose tratamiento con fluidoterapia intravenosa y antibioticoterapia de amplio espectro. Posteriormente se comenzó el tratamiento quirúrgico

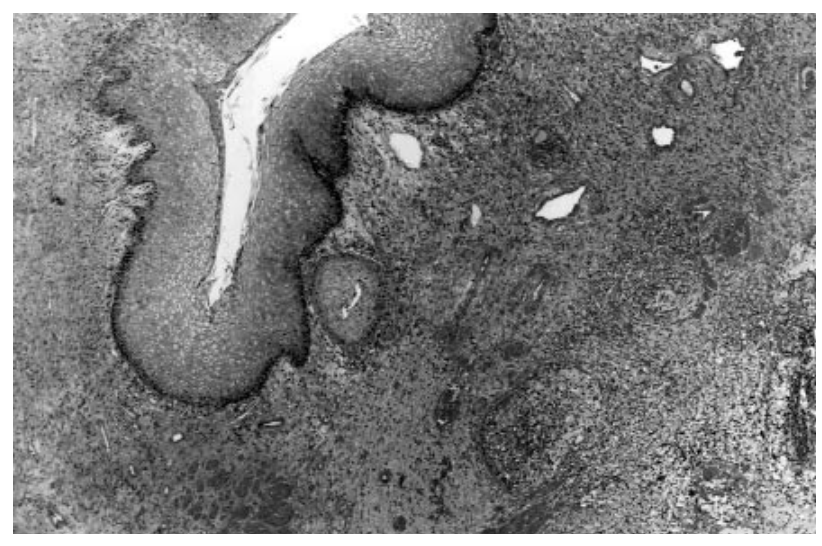

FIG URA 2. HE. 40X Infiltrado neutrofilico con necrosis tisular subepitelial 
(Figura 1), bajo anestesia general, y en posición de litotomía(previamente se colocó una talla vesical). La gangrena se extendía por toda la pared escrotal, con afectación perineal y de la uretra bulbar, apareciendo esta necrótica y llena de pus con extensión a la porción proximal de la uretra peneana. Se procedió a remover todo el tejido gangrenoso dejando abierta la uretra membranosa en la base de la herida, asimismo se drenó un absceso situado en la fosa isquiorectal izquierda. Se dejaron drenajes a nivel de dicha fosa y periné.

El estudio anatomopatológico de la pieza de resección segmentaria de la uretra (cinco centímetros), reveló la presencia de necrosis inflamatoria subepitelial. (Figura 2) En el cultivo del pus de la herida creció un Streptocccus Agalactiae.

Dos meses más tarde fue trasladado a otro Centro Hospitalario para reparación plástica del amplio defecto cutáneo perineoescrotal, realizándose una cobertura de la zona con un colgajo de gracilis bilateral.

A los cuatro meses y medio el paciente fue éxitus por una sepsis de origen biliar con fallo multiorgánico.

\section{DISCUSIÓN}

En 1883 Fournier describió cinco casos de "gangrena escrotal idiopática", un síndrome que desde entonces lleva su nombre. La descripción clásica era la gangrena escrotal de inicio explosivo, progresión rápida y ausencia de causas habituales de gangrena. $(1,3)$ En la mayoría de los casos publicados no había puerta de entrada evidente de la infección. Lo cual llevó a considerarla como "gangrena idiopática del escroto". Más recientemente, sin embargo, ha sido posible identificar en la mayoría de los casos una puerta de entrada para los microorganismos claramente definida (2). Se han comunicado casos de fascitis necrotizante siguiendo tanto infecciones perianales como abdominales, y se ha descrito gangrena genital después de extravasación urinaria o de flemones periuretrales. Es probable que en la mayoría de los casos de gangrena de Fournier, si no todos, la fuente de infección sea tanto el tracto urinario como anorectal.

La presencia de una enfermedad crónica o debilitante, como el alcoholismo o la diabetes, se cree también que puede predisponer al desarrollo de esta patología.

Los factores precipitantes de origen genitourinario más frecuentemente implicados en el desarrollo de una gangrena de Fournier son la estenosis uretral y la colocación, traumática 0 no, de catéteres uretrales. 0 tros trastornos urogenitales también se han relacionado con esta patología como los cálculos uretrales, masaje prostático, para- fimosis, orquitis y epididimitis y carcinoma vesical.

En el caso descrito, el hecho de que el portal de entrada de la infección sea una pérdida de continuidad uretral sirve para ilustrar una posible complicación severa de un intento de cateterización uretral en manos inexpertas. (6) La anatomía del periné, el pene y el escroto determina la diseminación de la destrucción tisular de la gangrena de Fournier. El periné se divide en dos triángulos: el triángulo urogenital (anterior) y el triángulo a norectal (posterior).

El triángulo urogenital está definido posteriormente por una línea imaginaria entre las tuberosidades isquiáticas, lateralmente por la rama isquiática y anteriormente por el púbis. La fascia de Colles está fija lateralmente a la rama pubiana y la fascia lata. Posteriormente, la fascia de Colles se fija a la fascia inferior del diafragma urogenital que se condensa en el cuerpo perineal. Estas inserciones tienden a confinar la diseminación posterior y lateral de la gangrena de Fournier. La fascia de Colles se convierte en la fascia de Scarpa en la pared abdominal inferior y en el dartos del pene y el escroto. Estas capas tisulares comunes son las que permiten la libre diseminación de la fascitis.

En la patogenia propuesta para la gangrena de Fournier de origen uretral, las bacterias procedentes del tracto urinario infectan las glándulas periuretrales. En las infecciones no tratadas, o en los huéspedes inmunodeprimidos, la infección, se puede extender hacia el cuerpo esponjoso, atraviesa la albugínea y alcanza la fascia de Buck. Si esta resulta dañada se produce la diseminación a través de la fascia del Dartos comprometiendo el escroto y el pene. También puede propagarse desde esta fascia hacia la fascia de Colles y la región perineal o hacia la fascia de Scarpa y la pared abdominal anterior. Más infrecuente resulta la extensión desde la fascia de Colles a la fosa isquirectal alcanzando el retroperitoneo y el espacio pararectal, aumentando la gravedad del proceso.(3)

La condensación de la fascia de Colles en el cuerpo perineal evita, de forma característica, la afectación del margen anal, a diferencia de las infecciones de origen anorectal. (3) Los testículos y los cuerpos cavernosos no suelen estar involucrados en el proceso necrótico, debido a su vascularización independiente, salvo en casos de gangrena muy evolucionados o cuando el foco infeccioso de sitúa en alguna de las siguientes localizaciones: orquitis, epididimitis, absceso escrotal e implantación de prótesis intracavernosa para disfunción eréctil. (3)

Independientemente de sí la gangrena de Fournier es de origen genitourinario, colorectal o idiopático, el acontecimiento inicial es el establecimiento de una infección local 
adyacente al punto de entrada. Esta se extiende a planos profundos y progresa rápidamente hacia la endarteritis obliterante característica, generando una necrosis vascular cutánea y subcutánea. La necrosis tisular resultante es secundaria a la isquemia y al efecto sinérgico de diferentes bacterias. $(1,7)$

La consecución de un medio hipóxico es determinante en la patogenia de esta gangrena, ya que la baja presión de oxígeno es fundamental en la proliferación de los microorganismos a naerobios característicos de ella. El consumo local de oxígeno por parte de los aerobios se combina con un menor aporte vascular secundario al edema y la inflamación, pudiendo ser clave la trombosis de los pequeños vasos subcutáneos. (7)

Por último debemos enfatizar en la necesidad de un desbridamiento radical y rápido, con una cobertura antibiótica de a mplio espectro, teniendo en cuenta la pérdida de longitud uretral en el caso de los desbridamientos de las gangrenas que afectan esta. $(4,5,8,9)$

\section{BIBUOGRAFIA Y LECTURAS}

RECOMENDADAS (*lectura de interés y

**lectura fundamental)

1. KARIM, M.S.: "Fournier gangrene following urethral necrosis by indwelling catheter". Urology, 23: 173, 1984.

2. SPIRNAK, J.P.; RESNICK, M.I.; HAMPEL, N. y cols.: "Fournier's gangrene: report of 20 patients". Journal of Urology, 131: 289, 1984.

*3. RODRIGUEZ ALONSO, A.; PÉREZ GARCÍA, M.D.; NUÑEZ LÓPEZ, A. y cols.: "Gangrena de Fournier : Aspectos anatomo-clínicos en el adulto y en el niño. Actualización terapéutica". Actas Urol. Esp., 24: 294, 2000.

4. HELLSTROM, W.; MONGA, M.; COTE, D. y cols.: "Reconstruction of a total anterior urethral defect using buccal mucosa". South Med. J., 89: 1088, 1996.

5. BECKENSTEIN, M.; SMITH, A.A.; DINCHMAN, K. y cols.: "Muscle flap reconstruction aids in urethral regeneration”. Ann. Plast. Surg., 36: 641, 1996.

6. CONN, I.G.; LEWI, H.J.E.: "Fournier's gangrene of the scrotum following traumatic urethral catheterisation”. J. R. Coll. Surg. Edinb., 32: 182, 1987.

7. CAMPOS, J.A.; MARTOS, J.A.; GUTIERREZ, R. y cols.: "Synchronus caverno-spongious thrombosis and Fournie`s gangrene”. Arch. Esp. de Urol., 43: 423, 1990.

8. WALKER, L.; CASSIDY, M.T.; HUTCHISON, A.G. y cols.: "Fournier's gangrene and urethral problems". British Journal of Urology, 56: 509, 1984.

9. KAMEI, Y.; AOYAMA, H.; YOKOO, K. y cols.: "Composite gastric seromuscular and omental Pedicle flap for urethral and scrotal recostruction after Fournier's gangrene”. Ann. Plast. Surg., 33: 565, 1994.
Casos Clínicos

Arch. Esp. Urol., 58, 2 (170-175), 2005

\section{“PRESENTACIÓN DE DOS CASOS: VESICAL Y PROSTÁTICO DE OAT-CEЦ"}

Juan José Ballesteros Sampol, Josep Loreta Trull, Cristina Ballesteros M onzó y Roberto Ja ramillo Velásquez

Servicios de Urología y Patología del Hospital de la Esperanza. Barcelona. España.

Resumen.- O BJETIVO : Presentar dos casos: vesical y prostático de "oat-cell" que siguieron una mala evolución como es habitual ver en las publicaciones que se han revisado con ese motivo.

M ÉTO DO / RESULTADO S: El caso de localización vesical se presentó asociado a diferenciación escamosa y adenocarcinoma. El tratamiento radical seguido de quimioterapia adyuvante no detuvo la fatal evolución que culminó a los 13 meses con un cuadro agudo séptico enmarcado por múltiples metástasis. El caso localizado en próstata debutó con una oligoanuria e hidronefrosis bilateral que fue preciso derivar de urgencia (nefrostomía) Una vez diagnosticado se transformó la derivación externa en interna para mejorar algo la confortabilidad del paciente. La quimioterapia sistémica no obtuvo respuesta alguna y se produjo el "exitus" a los 4 meses del diagnóstico.

CONCLUSIÓN:Los casos presentados se suman a la escasa presencia que, sobre esta patología, es posible

Juan José Ballesteros Sampol

Servicio de Urología

Hospital de la Esperanza

Sant Josep de la M ontaña, 12

08024 Barcelona. España.

e-mail: $18190 @$ imas.imim.es

Trabajo recibido: 20 de julio 2004 